\title{
Formação escolar e perfil sociológico do corpo docente do Colégio Estadual Dias Velho (1950-1964)
}

\author{
School background and sociological profile of the faculty school \\ from Colégio Estadual Dias Velho (1950-1964)
Formación escolar y perfil sociológico del cuerpo docente del Colégio Estadual Dias Velho (1950-1964)

\author{
NORBERTO DALLABRIDA*
}

\begin{abstract}
RESUMO - Este artigos e propõe a compreender a constituição do corpo docente dos cursos clássico e científico segundo ciclo do ensino secundário - do Colégio Estadual Dias Velho, entre 1950 e 1964, e as suas implicações na tessitura da cultura escolar praticada. À luz das reflexões sociológicas bourdieusianas e do conceito de apropriação de Roger Chartier são analisadas as formações escolares e as preferências culturais, políticas e religiosas desses professores. Para tanto, essa reflexão sócio-histórica usa documentos escolares escritos, matérias de jornais e, especialmente, depoimentos de ex-professores. O estudo do corpo docente do Colégio Estadual Dias Velho é contextualizado em nível regional e nacional.
\end{abstract}

Palavras-chave - Corpo docente. Ensino secundário. Apropriação.

\begin{abstract}
This article proposes to understand the constitution of the faculty school from the classic and cientific courses - second cicle of secondary education - from Colégio Estadual Dias Velho, between the years 1950 and 1964, and its implications on the texture of the school culture practiced. Aware of bourdesian sociological reflections and the concept of appropriation from Roger Chartier are analyzed the school background, and the cultural, political and religious preferences of these teachers. For that, this sociohistorical reflection uses written school documents, newspaper articles, and specially testimonial from former teachers. The study of the faculty school from Colégio Estadual Dias Velho is contextualized in regional and national level.
\end{abstract}

Keywords - Faculty school. Secondary education. Appropriation.

RESUMEN - Este artículo busca entender la formación del cuerpo docente de los cursos clásico y científico - según ciclo de la enseñanza secundaria - del Colégio Estadual Dias Velho, entre 1950 y 1964, y sus implicaciones en la producción de la cultura escolar practicada. A partir de las reflexiones sociológicas de Pierre Bourdieu y del concepto de apropiación de Roger Chartier son analizadas las trayectorias escolares y las preferencias culturales, políticas y religiosas de estos profesores. Este análisis socio histórico usa documentos escolares, artículos de periódicos y, especialmente, testimonios de antiguos profesores. El estudio del cuerpo docente del Colégio Estadual Dias Velho es contextualizado a nivel regional y nacional.

Palabras clave-Cuerpo docente. Enseñanza secundaria. Apropiación.

\footnotetext{
* Doutor em História Social pela Universidade de São Paulo (São Paulo, SP, Brasil) e Professor na Universidade do Estado de Santa Catarina (Florianópolis, SC, Brasil). E-mail: < norbertodallabrida@hotmail.com >.
} 


\section{INTRODUÇÃO}

Entre meados da década de 1940 e início dos anos 60 do século XX, no Estado de Santa Catarina, o subcampo do ensino secundário era formado por uma grande e vigorosa rede de educandários confessionais e somente alguns colégios públicos e gratuitos. Essa assimetria indica o empreendedorismo da Igreja Luterana e, especialmente, das ordens e congregações católicas, mas revela a tímida e tardia intervenção dos poderes públicos em relação ao ensino secundário. Depois de um longo período marcado pela privatização desse nível de escolarização, no início de 1947, o Estado de Santa Catarina implantou o curso ginasial - o primeiro ciclo do ensino secundário - no Instituto de Educação Dias Velho, localizado em Florianópolis, no Instituto de Educação de Lages e na Escola Normal Pedro II da cidade de Blumenau. Cinco anos depois, o Colégio Barão de Antonina, que havia sido fundado em Mafra, na década de 1930, foi comprado pelo Governo Estadual, que o transformou na Escola Normal Barão de Antonina, que também oferecia o curso ginasial. Desta forma, até o início da década de 1960, o ensino secundário de caráter público e gratuito somente era proporcionado nesses quatro estabelecimentos de ensino de formação de professores.

O Instituto de Educação Dias Velho, renomada escola de formação de professores/as de ensino primário, localizada na capital catarinense, implantou, a partir de 1950,os cursos clássico e científico, que integravam o colegial ou o segundo ciclo do ensino secundário, engendrando a criação um colégio público homônimo. Assim, o Colégio Estadual Dias Velho, que funcionava somente no período noturno e em regime de externato, afirmou-se como o principal estabelecimento de ensino secundário de caráter público, gratuito, coeducativo e de qualidade no Estado de Santa Catarina. Entre o início da década de 1950 e meados dos anos 60 do século XX, no subcampo ${ }^{1}$ do ensino secundário em Florianópolis, ele se diferenciava porque os outros dois educandários existentes eram católicos, distintos em gênero e com regime de internato. Trata-se do Colégio Catarinense, administrado pelos padres jesuítas, cuja clientela era formada somente por adolescentes homens, e o Colégio Coração de Jesus, dirigido pelas Irmãs da Divina Providência e voltado para adolescentes mulheres. Nessa configuração escolar, portanto, o Colégio Estadual Dias Velho tinha singularidade e relevância social.

O objetivo do presente artigo é compreender a constituição do corpo docente dos cursos clássico e científico do Colégio Estadual Dias Velho, entre 1950 e 1964, e as suas implicações na tessitura da cultura escolar praticada. Para tanto, são analisadas as formações escolares e as preferências culturais, políticas e religiosas desse corpo docente. A ano-limite inicial refere-se à implantação dos cursos clássico e científico no Colégio Estadual Dias Velho e, de outra parte, em 1964 deu-se a transferência desses cursos para novo e imponente prédio, viabilizando a massificação do ensino secundário, bem como ocorreu o golpe militar no Brasil. Em relação aos percursos escolares dos professores focaliza-se especialmente a formação em nível superior, considerando que boa parte dos docentes do ensino secundário, nas décadas de 50 e 60 do século XX, no Brasil, não tinha curso de licenciatura. Na constituição do corpo docente do antigo Colégio Estadual Dias Velho leva-se em conta também os gostos artístico-culturais, a escolha de ideologias e as adesões a religiões. As diversas escolhas dos professores reverberavam nas apropriações específicas da cultura escolar.

O presente estudo sócio histórico apoia-se nas reflexões sociológicas de Pierre Bourdieu, particularmente na sua "noção polimorfa de capital" (CHAUVIRÉ; FONTAINE, 2003). Para analisar trajetórias socioprofissionais de diferentes grupos sociais, além de considerar o capital econômico, Bourdieu (1998, p. 65-79) criou os conceitos de capital cultural e seus três estados (incorporado, objetivado e institucionalizado) e de capital social, entendido como uma rede durável de relações que exige um "trabalho de instauração e manutenção", que despende tempo, esforços e recursos financeiros, mas proporciona lucros materiais e simbólicos. Bourdieu (2001) também considera que há "efeitos simbólicos do capital" que conferem prestígio a indivíduos e instituições em campos específicos.

O conceito de apropriação é compreendido na perspectiva de Chartier (1990, 1992), que considera que os bens culturais são usados de forma diferente, de modo que a recepção é realizada com criatividade, por meio de resistências, ressignificações e arranjos. $\mathrm{O}$ foco é colocado sobre "os usos diferenciados e opostos dos mesmos bens culturais, dos mesmos textos e das mesmas ideias" (CHARTIER, 1992, p. 233). Nas instituições escolares os bens culturais também são apropriados de forma diferenciada e inventiva. A cultura escolar prescrita, formada por textos normativos que definem conhecimentos a serem ensinados e comportamentos a serem interiorizados, é apropriada pelas escolas na tessitura do fazer educativo, plasmando culturas escolares praticadas e singulares (JULIA, 2001; FARIA FILHO; VIDAL; PAULILO, 2004). Para compreender essas "apropriações específicas" da cultura escolar prescrita é imprescindível analisar a constituição e a atuação do corpo dirigente e docente das instituições escolares, bem como considerar a intervenção dos estudantes no cotidiano escolar. 
Dessa forma, inicialmente este trabalho coloca o foco sobre a formação escolar dos professores do Colégio Estadual Dias Velho, procurando constatar os cursos que eles frequentaram, especialmente em nível superior. Considera-se que, nas décadas de 1950 e 1960, no Brasil, predominavam os professores leigos e o ensino secundário, além de ser elitizado, viveu um período de transição entre o humanismo da Lei Orgânica do Ensino Secundário (1942) e os processos de modernização que se colocaram em marcha desde a década de 1950, particularmente aqueles implementados pelo Ministério da Educação e Cultura e, particularmente, pelo Instituto Nacional de Estudos Pedagógicos (MENDONÇA; XAVIER, 2008). Por outro lado, reflete-se sobre a diversidade dos lentes catedráticos - docentes efetivados por meio de concurso público - e professores contratados do Colégio Estadual Dias Velho, procurando compreender implicações das escolhas políticas, culturais e religiosas na feitura da cultura escolar.

\section{"UM MAGISTÉRIO DE EMERGÊNCIA"}

No Brasil, os colégios jesuíticos do período colonial e os liceus do oitocentos, bem como os ginásios da Primeira República, foram marcados pelo caráter elitista e propedêutico, contrapondo-se ao ensino técnico. A Reforma Francisco Campos (1931) imprimiu ao ensino secundário um ritmo moderno e criou condições para o seu crescimento, que foi realizado sobremaneira por colégios confessionais (DALLABRIDA, 2009). No entanto, após a Reforma Capanema (1942) houve uma expansão significativa do ensino secundário, especialmente do segundo ciclo, que preparava e habilitava para o ingresso no ensino superior. A respeito desse processo, Pinto (2008, p. 150) afirma:

As escolas secundárias passaram então a ser procuradas por todos aqueles que desejavam ascender socialmente. Contrariando sua finalidade elitista, o ensino secundário cresceu assustadoramente após a Reforma Capanema em todo o país. Na década de 1942-1952, a expansão do ensino secundário foi de $210 \%$ no primeiro ciclo [ginasial] e de $436 \%$ no segundo ciclo [colegial] no que se refere a matrículas. Em relação ao número de unidades, essa expansão foi de $1.084 \%$ e $498 \%$, respectivamente.

Essa tendência se acentuou no período da redemocratização, pois, segundo Nunes (2000, p. 45), em 1945 a matrícula geral dos alunos do ensino secundário era de 237.695, mas, em 1960, havia saltado para 991.391.É importante destacar algumas particularidades dessa situação. Em primeiro lugar, a maior concentração de alunos do ensino secundário dava-se no primeiro ciclo, que, em 1954, chegava a $85,8 \%$ do total do alunado, indicando que havia um número muito grande de ginásios, inclusive nas cidades médias e pequenas, e um número reduzido de colégios, concentrados especialmente nas grandes cidades. Em segundo lugar, no segundo ciclo havia uma assimetria grande entre o clássico e científico, sendo que a grande maioria dos estudantes optava por este último curso (SOUZA, 2008, p. 204-205). O curso científico preparava e habilitava os estudantes ao ingresso em cursos superiores de elite como Medicina e Engenharia. Em terceiro lugar, nos anos 40 e 50 do século XX, apesar de certo avanço dos setores públicos, o ensino secundário ainda era dominado pela rede privada, especialmente pelas escolas confessionais. Por fim, deve-se considerar que na distribuição do ensino secundário havia uma grande desproporção regional, pois, segundo Nunes $(2000$, p. 46), em 1960, a região sudeste concentrava " $60 \%$ da matrícula total do ensino secundário, $56 \%$ do total dos estabelecimentos do país".

A expansão do ensino secundário nas décadas de 1940 e 1950 agravou ainda mais o problema da grande insuficiência de professores licenciados, o que levou o Governo Federal a criar "um magistério de emergência", recrutado por meio do exame de suficiência. Essa prova, instituída pelo Decreto-Lei 8.777, de 22 de janeiro de 1946, tornava aptos os professores secundaristas a lecionar onde não houvesse docentes devidamente formados pela Faculdade de Filosofia, Ciências e Letras. Até meados da década de 1950, o exame de suficiência era aplicado nas faculdades de filosofia, de forma que habilitava somente 520 professores para lecionar nos colégios de ensino secundário (PINTO, 2008, p. 151-157). Dessa forma, o exame de suficiência atingia uma parcela muito restrita dos docentes do ensino secundário, porque havia poucas faculdades de filosofia - localizadas nas grandes cidades. Sobre essa situação, Nunes (2000, p. 46) assevera:

Tal crescimento [do ensino secundário] provocou a super utilização do professorado e apesar das medidas destinadas a tornar o magistério secundário um grupo ocupacional estável e numericamente importante (tais como o registro profissional, a regulamentação das condições de trabalho e a criação das Faculdades de Filosofia), a maior parte dos professores desse nível de ensino utilizava o magistério como ocupação parcial. $\mathrm{O}$ crescimento da rede e das matrículas provocou o crescimento do corpo docente, que passou a ser recrutado por uma série de processos emergenciais.

Na gestão de Armando Hildebrand frente à Diretoria do Ensino Secundário (DESE), marcada por iniciativas de modernização do ensino secundário, foi criada a Campanha de Aperfeiçoamento e Difusão do Ensino Secundário (CADES), sendo instituída pelo Decreto 
34.638, de 17 de novembro de 1953. A CADES é parte integrante do chamado "campanhismo", estratégia emergencial do Ministério da Educação e Cultura na década de 1950, do qual fez parte, entre outras, a Campanha do Livro Didático e Manuais de Ensino (CALDEME) e a Campanha de Levantamentos e Inquéritos para o Ensino Médio e Elementar (CILEME) (XAVIER, 2008). As principais atividades previstas nesse decreto para a CADES eram a realização de cursos de aperfeiçoamento de docentes, técnicos e diretores, a promoção de estudos dos programas e dos métodos do ensino secundário, a efetivação serviço de Orientação Educacional criado pela Reforma Capanema e a promoção de intercâmbios entre escolas e educadores no Brasil e no exterior. Os primeiros "cursos de orientação de professores" foram realizados nos meses de janeiro e fevereiro - período de férias de 1954 e, no ano seguinte, os exames de suficiência passaram a ser de competência da DESE, o que permitiu a sua realização onde não houvesse faculdade de filosofia, ampliando a sua abrangência em nível nacional (PINTO, 2008, p. 152-157).

Entre 1956 e 1964, a CADES teve um período de ouro, quando houve expansão e consolidação dos cursos intensivos de férias para professores visando ao exame de suficiência, foi implantada a orientação educacional no ensino secundário e foi produzida uma bibliografia específica, com destaque para a revista "Escola Secundária", as séries "Didáticas Especiais" e os "Cadernos de Orientação Educacional" (PINTO, 2008, p. 157-171). Entretanto, com o golpe militar de 1964, a CADES começou o declínio que a levaria à extinção, processo que estava estruturalmente ligado à expansão e interiorização do ensino superior que se colocou no Brasil a partir da segunda metade da década de 1960.

Desta forma, a presença dos chamados "professores leigos" no ensino secundário era uma realidade em nível nacional. Os docentes sem formação específica para as disciplinas que ministravam geralmente faziam o curso intensivo e se submetiam ao exame de suficiência promovido pela CADES. As faculdades de Filosofia, Ciências e Letras tiveram um crescimento expressivo, mas mesmo assim, em 1960, somente cerca de 30\% do total de professores do ensino secundário no país eram licenciados (SOUZA, 2008, p. 212). A qualidade de boa parte dessas faculdades, especialmente aquelas localizadas nas médias e pequenas cidades, era questionada devido à falta de cultura acadêmica. Nesta direção, Nunes (1962, p. 126-127) constata que "as faculdades de Filosofia, destinadas à formação do professorado secundário, brotam numerosas pelo país, na sua maioria em cidades onde não há condições culturais para que existam". Em relação à formação dos professores do ensino primário, realizado no mínimo desde o início do regime republicano em escolas normais e institutos de educação, a preparação universitária dos professores do ensino secundário até a década de 1960 era muito limitada e precária.

Como se pode observar no Quadro1, a maioria dos professores dos cursos clássico e científico do Colégio Estadual Dias Velho não tinha formação em nível superior na área específica em que atuava e vários deles foram habilitados para as suas disciplinas específicas por meio do exame de suficiência da CADES (SERPA, 2011, p. 1-2). Neste quadro pode-se constatar que a maior frequência no ensino superior desses docentes era a Faculdade de Direito, seguido pelos cursos de Filosofia e Engenharia. A formação específica em nível superior era exceção à regra, como o Curso de Letras e a Escola de Belas Artes, sendo realizada em outros estados da federação brasileira. Essa situação deve-se ao fato de Florianópolis ter implantado muito tardiamente instituições de ensino superior, pois a Faculdade de Direito é de 1932 (BARBOSA, 1982), os cursos de Ciências Econômicas e de Odontologia e Farmácia foram criados na década de 1940, e a Faculdade Catarinense de Filosofia abriu as suas portas somente em 1955, resultado do trabalho de um grupo de professores do Curso de Direito de Florianópolis. Essa última faculdade passou a oferecer os cursos de Filosofia, História, Geografia, Letras (Clássicas, Neolatinas e Anglo-Germânicas), frequentados por um número muito pequeno de alunos, e tinha a sua sede no Colégio Catarinense - dirigido pelos padres jesuítas (CARMINATI, 2010).

No início de 1960, a Faculdade Catarinense de Filosofia passou a oferecer o Curso de Didática, que capacitava os bacharéis para o exercício docente no ensino secundário, e teve 48 alunos matriculados, indicando que havia uma demanda reprimida na formação docente em nível superior. No final daquele ano foi criada, em Florianópolis, a Universidade Federal de Santa Catarina (UFSC), que incorporou a Faculdade Catarinense de Filosofia, passando a ser chamada de Faculdade de Filosofia, Ciências e Letras e teve crescimento expressivo da sua estrutura e do seu corpo docente. Assim, a predominância dos professores leigos no ensino secundário começou a se alterar, efetivamente, com a implantação da UFSC - Universidade pública e gratuita -, que passou a formar licenciados para a quase totalidade de disciplinas do ensino secundário.

No período entre o início da década de 1950 e meados dos anos 60 do século XX, a maioria dos professores do Colégio Estadual Dias Velho não tinha formação em nível superior na área específica da sua atuação docente, mas em Direito e Engenharia, entre outras. O corpo docente do Colégio Estadual Dias Velho, portanto, era formado especialmente por professores leigos, sendo que vários se qualificaram por meio do exame de suficiência da CADES. 
Quadro 1 - Formação escolar e disciplinas lecionadas por professores no ciclo colegial do Colégio Estadual Dias Velho (1950-1964)

\begin{tabular}{|c|c|c|}
\hline Nome do/a professor/a & Formação escolar & Disciplina lecionada \\
\hline Aldo João Nunes & Escola de Belas Artes & Desenho \\
\hline Anacleto Damiani & Ensino Secundário & Matemática \\
\hline Aníbal Nunes Pires & Bacharel em Direito & Português \\
\hline Aujor Ávila da Luz & Medicina & História \\
\hline Aurea Miranda da Cruz & Curso Normal & Francês \\
\hline Celestino Sachet & Bacharel em Direito & Espanhol, Francês \\
\hline Custódio Francisco de Campos & Bacharel em Direito & Latim \\
\hline Eglê Malheiros & Bacharel em Direito & História \\
\hline Hélio Barreto dos Santos & Bacharel em Direito & Latim \\
\hline Jaldir Faustino B. da Silva & Bacharel em Direito & História \\
\hline Januário Raimundo Serpa & Filosofia & Filosofia \\
\hline João Batista Luft & $\begin{array}{l}\text { Licenciatura em Letras Anglo-Germânicas } \\
\text { Ciências Econômicas }\end{array}$ & Matemática \\
\hline João Kryssakis (padre ortodoxo) & Teologia & Grego \\
\hline José Martins Neto & Ensino Secundário & Física Química \\
\hline José Warken Filho & Curso Normal & Geografia \\
\hline Maria Carolina Galotti Kehrig & Licenciatura em Letras Neolatinas & Português \\
\hline Nilson Elias Paulo & Engenharia Química & Física \\
\hline Orlando Ferreira de Melo & Bacharel em Direito & Português \\
\hline Osvaldo Ferreira de Melo & Bacharel em Direito & Português \\
\hline Pedro José Bosco & Curso Normal & Matemática \\
\hline Rodolfina Moritz Treska Moellmann & Curso Primário na Escola Alemã de Florianópolis & Francês \\
\hline Tarcísio Marchiori (padre católico) & Filosofia & Filosofia \\
\hline Walmir Dias & Engenharia Química & Química \\
\hline Wilmar Orlando Dias & Bacharel em Direito & Geografia \\
\hline
\end{tabular}

Fontes: Colégio... (1956), Barbosa (1982), Rosa e Madeira (1982, p. 151), Colégio... (2005), Carminati (2010), Serpa (2011).

\section{DIVERSIFICAÇÃO DO CORPO DOCENTE}

Como parte integrante do sistema de ensino público do Estado de Santa Catarina e devido à ausência específica de formação docente para o ensino secundário, o Colégio Estadual Dias Velho selecionava os seus professores por meio de concurso público. O professor do ensino secundário admitido por concurso público era chamado de lente catedrático, tinha prestígio no campo escolar e distinção social, diferenciando-se do professor contratado. Segundo Dias (2008, p. 185-203), essa clivagem podia ser constatada nos concursos de seleção e nas sessões solenes dede posse dos lentes catedráticos, que recebiam a cobertura da imprensa escrita - particularmente no Colégio Pedro II do Rio de Janeiro. Em 1957 foi criada a "Congregação do Instituto de Educação e Colégio Estadual Dias Velho", a instância representativa do corpo docente em relação às questões administrativas e pedagógicas, que deveria ser formada por 25 membros, escolhidos entre os lentes catedráticos mais antigos em cada disciplina, tendo como presidente o diretor do educandário (CRIADA..., 1957, p. 1).
Segundo os depoimentos dos ex-professores Celestino Sachet (2010, p. 2-5)e Osvaldo Ferreira de Melo (2010, p. 4-5), no Colégio Estadual Dias Velho havia um clima de liberdade, cordialidade e respeito mútuo, mas o seu corpo docente era marcado pela diversidade ideológica e religiosa, própria da seleção por concurso público. Havia professores católicos, espíritas e até um cristão ortodoxo - João Khryssakis -, que era titular de Grego, mas ninguém fazia proselitismo religioso. Havia também um pequeno grupo de professores comunistas, como Eglê Malheiros, Anacleto Damiani e José Martins Neto, que tinham vinculações com o Partido Comunista Brasileiro (PCB). Este último docente era conhecido na cidade de Florianópolis como "professor Martins", lecionava Física e Química e ocupou a função de tesoureiro no PCB (MARTINS, 1995, p. 207-210). Pelo fato de ser militante socialista e filiada ao PCB, a professora Eglê Malheiros sofreu processos judiciais, junto com o professor Martins, movidos por denúncias de colegas ou de pais de alunos. Com o golpe militar de 1964 ela foi afastada do Colégio Estadual Dias Velho e "colocada em disponibilidade", retornando à sua função docente quinze anos depois, 
quando ocorreu a anistia política (MALHEIROS, 2009, p. 5,8 e 20).

Além da diversidade religiosa e política, o corpo docente do Colégio Estadual Dias Velho apresentava alguns perfis inusitados de professores de ensino secundário em Santa Catarina. Entre 1944 e 1945 e 1950 e 1951, a diretora-geral do Instituto de Educação Dias Velho e colégio estadual homônimo foi Antonieta de Barros, afrodescendentes, cronista e professora de português, que, em 1934, tinha sido a primeira mulher eleita para o legislativo catarinense. Como diretora, ela acompanhou o processo de criação dos cursos clássico e científico, viabilizando a instituição do Colégio Estadual Dias Velho. No início da década de 1930, a professora Antonieta de Barros havia defendido a criação de um curso secundário para mulheres, que se concretizaria, sob a sua direção, no Colégio Estadual Dias Velho, que acolhia indistintamente adolescentes homens e mulheres (NUNES, 2001, p. 256257). Ademais, segundo Malheiros (2009, p. 9), entre os professores do Colégio havia alguns que eram separados de seus parceiros conjugais, que certamente não seriam aceitos nos colégios católicos.

Alguns professores do Colégio Estadual Dias Velho, como Eglê Malheiros, Aníbal Nunes Pires, Aldo Nunes e Osvaldo Ferreira de Melo participavam do "Círculo de Arte Moderna", que editou a revista SUL, entre 1948 e 1957, sendo, por isso, mais conhecido como Grupo SUL (SABINO, 1981, p. 24-36; MELO, 2010, p. 2). Aníbal Nunes Pires foi o principal diretor da revista SUL e principal líder do grupo modernista de Florianópolis (CORRÊA, 2006, p. 31). Aliás, o Instituto de Educação Dias Velho abrigou, em 1948, a primeira exposição de arte contemporânea na pacata cidade de Florianópolis, a qual contou com telas de Portinari e foi promovida pelo Grupo SUL, que no início daquele ano havia lançado o primeiro número da sua revista. Tal mostra de arte moderna chocou boa parte da intelectualidade da capital catarinense, reunida sobretudo na Academia Catarinense de Letras, e entusiasmou o Grupo SUL e boa parte da juventude. Além de tonificar a disputa no campo artístico catarinense, essa exposição engendrou a fundação do Museu de Arte de Santa Catarina (MIGUEL, 2008).

A diversidade da formação política, religiosa e cultural do corpo docente do Colégio Estadual Dias Velho proporcionava apropriações diversificadas da cultura escolar prescrita pela Lei Orgânica do Ensino Secundário. Por exemplo, a disciplina História, ministrada pela professora Eglê Malheiros, militante comunista e integrante do Grupo SUL, diferenciava-se dos professores de História dos estabelecimentos de colégios católicos de Florianópolis e mesmo do Colégio Estadual Dias Velho. Ela considera que os livros didáticos de História da sua época eram muito factuais e descontextualizados, por isso estimulava a leitura de outros livros com o objetivo de "desenvolver o espírito crítico" e adotava "uma perspectiva marxista", apoiando-se especialmente nas obras Formação política do Brasil e História econômica do Brasil, de Caio Prado Júnior. Sobre a sua prática como docente (MALHEIROS, 2009, p. 3) afirma:

Era comum pedirem para as crianças decorarem quais tinham sido os governadores gerais, com a data exata, e não se falava em latifúndio, em monocultura, em pacto colonial; eu já abordava esses tópicos e me baseava muito no Caio Prado Júnior e outros historiadores.

A formação escolar e a diversidade política, cultural e religiosa do seu corpo docente, bem como a prática da coeducação, conferiam ao Colégio Estadual Dias Velho, nas décadas de 1950 e 1960, uma atmosfera escolar cosmopolita. Havia professores que professavam diferentes religiões, vários tinham conexões com o modernista Grupo SUL e três tinham vinculação à ideologia comunista. A matização na constituição desse corpo docente contribuía para tonificar o Colégio Estadual Dias Velho como um espaço público, marcado pela laicidade e alteridade, com exceção do período iniciado pelo golpe militar de 1964, quando as paixões políticas se acirraram. Em relação aos professores, constata-se uma diferença flagrante em relação aos outros dois estabelecimentos de ensino secundário de Florianópolis, ambos católicos e com um corpo docente mais estável, homogêneo e generificado.

\section{CONSIDERAÇõES FINAIS}

Pelo fato de serem selecionados por concurso público para o único colégio de ensino secundário público e gratuito localizado na capital de Santa Catarina, os lentes catedráticos do Colégio Estadual Dias Velho constituíam um quadros ócio profissional que tinha prestígio social. Para ter formação escolar no curso normal, no ensino secundário e, especialmente, em nível superior, eles geralmente eram oriundos de famílias com expressivo capital econômico e/ou cultural e/ou social. Contudo, esses professores formavam um corpo docente de emergência, pois a grande maioria não tinha formação universitária específica na área que atuava, mas era formada em diversificados cursos superiores e boa parte dela obteve o registro profissional por meio do exame de suficiência da CADES. Com esse quadro docente, o Colégio Estadual Dias Velho proporcionava uma escolarização secundária pública, laica e de qualidade, que viabilizou percursos escolares em nível superior e trajetórias sócio profissionais exitosas de alunos egressos, que geralmente eram oriundos da classe média. 
Essa configuração docente socialmente distinta começou a ser alterada no início da década de 1960. Em primeiro lugar, devido à implantação da Universidade Federal de Santa Catarina, em 1961, e da criação da Faculdade de Educação da Universidade do Estado de Santa Catarina (1963), que atraiu professores que atuavam no ensino secundário, de forma que vários deles se desligaram total ou parcialmente do Colégio Estadual Dias Velho. Em segundo lugar, deve-se considerar que houve o início da massificação do ensino secundário em Santa Catarina, alavancada pelo Plano de Metas do Governo - PLAMEG (1961-1965). Nesse movimento, em 1964, o Colégio Estadual Dias Velho ganhou um moderno e imponente edifício, que viabilizou a matrícula para milhares de alunos, provocando a contratação de dezenas de novos professores. Por fim, pelo fato de o golpe militar de 1964 desligar de suas funções docentes professores considerados subversivos, como a professora Eglê Malheiros.

Em comparação com o magistério do ensino primário, historicamente formado em escolas normais ou em institutos de educação e cursos de licenciatura em Pedagogia, o professorado do ensino secundário/médio é pouco investigado pela historiografia da educação no Brasil. Nesta direção, o presente artigo tem certo pioneirismo nos estudos pedagógicos e históricos em Santa Catarina e, por isso, engendra a possibilidades de desdobramento de novas investigações. Por um lado, é instigante ampliar a compreensão das relações entre perfil sociológico e apropriações da cultura escolar prescrita de diferentes professores no Colégio Estadual Dias Velho. De outra parte, vislumbra-se a possibilidade de ampliar a análise da formação escolar e o perfil sociológico de professores de outros estabelecimentos de ensino secundário em Florianópolis. No momento atual em que o professor está no centro da pauta da Educação Básica brasileira, a investigação científica sobre a formação docente é oportuna e necessária.

\section{REFERÊNCIAS}

BARBOSA, Renato. Cofre aberto...: reminiscências da Faculdade de Direito e outros assuntos (no cinquentenário da sua fundação). Florianópolis: Imprensa Universitária, 1982.

BOURDIEU, Pierre. La noblesse d'état: grandes écolesetesprit de corps. Paris: LesÉditions de Minuit, 1989. (Le senscommun).

III - O capital social. Capítulo. IV - Os três estados do capital cultural. In: NOGUEIRA, Maria Alice; CATANI, Afrânio (Org.). Escritos de educação. Petrópolis: Vozes, 1998. p. 65-79. Brasil, 2001.

Meditações pascalianas. Rio de Janeiro: Bertrand CARMINATI, Celso João. Cursos, disciplinas e primeiros professores da Faculdade Catarinense de Filosofia. Florianópolis. 2010. Trabalho inédito.
CHARTIER, Roger. A história cultural: entre práticas e representações. Lisboa: Difel, 1990.

VI. Textos, impressões, leituras. In: HUNT, Lynn (Org.). A nova história cultural. São Paulo: Martins Fontes, 1992. p. 211-238.

CHAUVIRÉ, Christiane; FONTAINE, Olivier. Le vocabulaire de Bourdieu. Paris: Ellipses, 2003.

COLÉGIO CATARINENSE. Livro dos formandos: cem anos do Colégio Catarinense. Florianópolis: Colégio Catarinense, 2005.

COLÉGIO ESTADUAL DIAS VELHO. Convite de formatura do Curso Científico da Turma de 1956. Florianópolis, 1956.

CORRÊA, Carlos Humberto. O Gama Rosa do século XX. In: MALHEIROS, Eglê et al. (Org.). Aníbal Nunes Pires: educação e literatura. Florianópolis: Editora da UFSC, 2006. p. 31-33.

CRIADA a Congregação do Instituto de Educação e Colégio Estadual Dias Velho. A Gazeta, Florianópolis, $12 \mathrm{dez}$. 1957 , p. 1

DALLABRIDA, Norberto. A Reforma Francisco Campos e a modernização nacionalizada do ensino secundário. Educação - Revista da Faculdade de Educação e do Programa de PósGraduação em Educação da PUCRS, Porto Alegre, v. 32, n. 2, p. 185-191, maio/ago.2009.

DIAS, Amália. Apostolado Cívico e trabalhadores do ensino: história do magistério do ensino secundário no Brasil (19311946). 2008. 251f. Dissertação (Mestrado em Educação) Programa de Pós-Graduação em Educação - Universidade Federal Fluminense, Niterói, 2008.

FARIA FILHO, Luciano Mendes de; VIDAL, Diana Gonçalves; PAULILO, André Luiz. A cultura escolar como categoria de análise e como campo de investigação na história da educação. Educação \& Pesquisa, São Paulo, v. 30, n. 1, p. 139-159, jan./ abr. 2004.

JULIA, Dominique. A cultura escolar como objeto histórico. Revista Brasileira de História da Educação, Campinas, n. 1, p. 9-43, 2001.

MALHEIROS, Eglê. Entrevista concedida a Norberto Dallabrida. Florianópolis, 8 de jun. 2009.

MARTINS, Celso. Os comunas: Álvaro Ventura e o PCB Catarinense. Florianópolis: Paraleto 27; Fundação Franklin Cascaes, 1995

MELO, Osvaldo Ferreira. Entrevista concedida a Norberto Dallabrida. Florianópolis, 14 jun. 2010.

MENDONÇA, Ana Waleska; XAVIER, Libânia Nacif (Org.). Por uma política de formação do magistério nacional: o INEP/MEC dos anos 1950/60. Brasília: Instituto Nacional de Estudos e Pesquisa Educacionais Anísio Teixeira, 2008. (INEP 70 anos, 1)

MIGUEL, Salim. Masc sessentão: a atuação de Marques Rebelo e do grupo da revista SUL na fundação do Museu de Arte de Santa Catarina. Diário Catarinense, Florianópolis, 3 maio 2008. Cultura, p. 2.

NUNES, Clarice. O "velho" e "bom" ensino secundário: momentos decisivos. Revista Brasileira de Educação, Rio de Janeiro, p. 35-60, maio/ago. 2000. 
NUNES, Karla Leonora Dalise. Antonieta de Barros: uma história. In: MORGA, Antônio. História das mulheres de Santa Catarina. Chapecó: Argos, 2001. p. 250-268.

NUNES, Maria Tetis. Ensino secundário e sociedade brasileira. Rio de Janeiro: INEP, 1962.

PINTO, Diana Couto. Campanha de Aperfeiçoamento e Difusão do Ensino Secundário: uma estratégia bem-sucedida? In: MENDONÇA, Ana Waleska; XAVIER, Libânia Nacif (Org.). Por uma política de formação do magistério nacional: o INEP/MEC dos anos 1950/60. Brasília: Instituto Nacional de Estudos e Pesquisas Educacionais Anísio Teixeira, 2008. p. 145-177. (INEP 70 anos, 1)

ROSA, José Edu; MADEIRA, Ademar Américo. Odontologia catarinense: evolução, ensino e movimento associativo. Florianópolis: Editora da UFSC, 1982.

SABINO, Lina Leal. Grupo Sul: o modernismo em Santa Catarina. Florianópolis: Fundação Catarinense de Cultura, 1981.

SACHET, Celestino. Entrevista concedida a Norberto Dallabrida. Florianópolis, 13 maio 2010.

SERPA, Januário. Entrevista concedida a Norberto Dallabrida. Florianópolis, 27 jan. 2011.
SOUZA, Rosa Fátima de. História da organização do trabalho escolar e do currículo no século $\mathbf{X X}$ (ensino primário e secundário no Brasil). São Paulo: Cortez, 2008.

XAVIER, Libânia Nacif. Qualificação de professores em três campanhas do Ministério da Educação no decênio 1950-1960 In: MENDONÇA, Ana Waleska; XAVIER, Libânia Nacif (Org.). Por uma política de formação do magistério nacional: o INEP/MEC dos anos 1950/60. Brasília: Instituto Nacional de Estudos e Pesquisas Educacionais Anísio Teixeira, 2008. (INEP 70 anos, 1). p. 127-143.

\section{NotA}

\footnotetext{
1 O conceito de campo como "microcosmo social" que tem autonomia relativa, constituído por leis, jogos e capitais específicos (CHAUVINÉ; FONTAINE, 2003, p. 16-19), é apoiado em Pierre Bourdieu. Na obra La noblessed'état (1989), ele utiliza o conceito de subcampo para analisar as grandes écoles - instituições de educação superior, independentes das universidades, que têm por objetivo formar as elites dirigentes e intelectuais - no campo do ensino superior francês. No presente trabalho o ensino secundário é considerado um subcampo do campo escolar.
}

Artigo recebido em fevereiro 2013. Aprovado em novembro 2013. 